Urban Water Systems \& Floods II 39

\title{
SIMULATION OF CHLORINE CONCENTRATION CHANGES IN A REAL WATER SUPPLY NETWORK USING EPANET 2.0 AND WATERGEMS SOFTWARE PACKAGES
}

\author{
BEATA KOWALSKA ${ }^{1}$, EWA HOLOTA ${ }^{2}$ \& DARIUSZ KOWALSKI ${ }^{1}$ \\ ${ }^{1}$ Environmental Engineering Faculty, Lublin University of Technology, Poland \\ ${ }^{2}$ Institute of Environmental Engineering, Social Sciences Faculty in Stalowa Wola, \\ John Paul II Catholic University of Lublin, Poland
}

\begin{abstract}
Chlorination is one of the most popular disinfection method to prevent its microbiological recontamination in water distribution systems. To ensure efficiency of disinfection and manage disinfectant concentrations throughout the network, it is important to keep the concentration of chlorine residual at an appropriate minimum level. It is particularly difficult in large water supply systems, especially at the ends of the network. There are many mathematical models simulating changes of chlorine decay in a water supply system in various operating conditions of the network. To predict chlorine concentration within distribution system it is necessary to determine a bulk and wall reaction parameters. In this paper the simulations of chlorine concentration changes have been performed in a selected part of the real water distribution system using EPANET 2.0 (US EPA) and WaterGEMS (Bentley) software packages. Calibrated hydraulic model, consisting of 1092 nodes and 1332 links, has been used as a base for building a quality model. For quality model calibration purposes, the values of chlorine concentrations in the chosen, characteristic points of water network were estimated by field measurements. Bulk decay coefficient were determined in the laboratory tests. Chlorine decay in a water distribution system was described by first-order kinetic model, which is currently often used to describe both bulk and wall chlorine consumption. The assessment of compliance of the values of chlorine concentrations within the network obtained as a result of simulations in both software packages with field measurements have been presented. The changes of chlorine concentration mean values obtained in both software packages are similar. A slightly better adjustment of the calculations to the measured values was obtained in the WaterGEMS software. The best adjustment of the simulated values with field measurements was obtained for the points closest to the water supply stations in both software packages.
\end{abstract}

Keywords: water quality, water distribution system, modelling.

\section{INTRODUCTION}

Disinfecting drinking water is considered important for the maintenance of water quality in distribution systems. Chlorine is the most widely used disinfectant due to its low cost, stability, and effectiveness [1]. Free chlorine can control growth of pathogens but it reacts with natural organic matter present in water, and generates by-products including potentially carcinogenic THMs [2]-[4]. The chlorine concentration decreases gradually in time as the treated water conveys through the pipe networks. Understanding the factors contributing to the loss of chlorine and the formation of disinfection by-products is a necessary to maintain chlorine residual levels in water distribution [5].

The decay of chlorine is mainly affected by water quality parameters like initial chlorine concentration, contents of organic and inorganic matters, temperature, iron content and so on e.g. [6]-[8] and networks parameters like hydraulic conditions, pipe materials and operating time of pipes e.g. [9]-[12]. The phase of chlorine loss could be mainly divided by chlorine bulk decay, characterized by reaction coefficient $\mathrm{k}_{\mathrm{b}}$ and wall decay, characterized by $\mathrm{k}_{\mathrm{w}}$ coefficient because the reactions can occur both within the bulk flow and with material along the pipe wall. Bulk decay coefficient depends on the nature of the source water and the 
treatment it has received while wall decay coefficient depends on the pipe [13]. $\mathrm{K}_{\mathrm{b}}$ reaction coefficient can be obtained by taking bottles of sample water before entering the network and conducting the bottle test in a laboratory [14]. Pipe wall coefficient $\left(\mathrm{k}_{\mathrm{w}}\right)$ is closely related to pipe material and pipe wall physical conditions such as encrustation and tuberculation of corrosion products.

A number of models have been developed to predict chlorine decay in drinking water networks [1], [3], [4], [15]. Musz et al. [16] reviewed the most popular models of water quality in distribution systems used in environmental engineering practice. Roopali et al. [17] reviewed the chlorine decay models in chronological order. Most mathematical models are based on some assumptions such as first-order decay, second order decay, power-law decay (nth order) and exponential decay or reacting balance equation to simulate the decay of chlorine concentration throughout the water distribution system e.g. [18]-[23]. First order decay model has been widely used to predict chlorine decay because of its simplicity and its reasonable accuracy to represent chlorine decay in water systems [5]. It allows to calculate the concentration of chlorine in the water $C$ throughout time $t$ when we know the chlorine concentration at the beginning $C_{o}$ :

$$
C=C_{0} \exp (-k t)
$$

where: $k\left[\mathrm{~d}^{-1}\right]$ is the overall chlorine decay coefficient, $k=k_{b}+k_{w}$ (e.g. [15], [24]).

There are now many modeling software packages which use the models discussed above to perform water quality simulations in the water distribution system, like EPANET, AQUIS, H2ONET, InfoWorks WS, MikeNet, Pipe2000, WaterGEMS/WaterCAD and so on [25]. The water quality model can be used as effective tool by water companies for the prediction of residual chlorine within the network on an effective level avoiding disinfection byproducts and the microbial contamination. Although many efforts have been made in the last decades, the modeling chlorine residuals is still complex and relies on many factors.

The purpose of this study is to predict chlorine residual in a part of a distribution network using EPANET 2.0 and WaterGems software. For the simulation a calibrated hydraulic model of the network, consisting of 1092 nodes and 1332 links, has been used. Laboratory tests were also carried out to determine the coefficient of bulk decay of chlorine $\mathrm{k}_{\mathrm{b}}$. Wall decay values $\mathrm{k}_{\mathrm{w}}$ were estimated through chlorine calibration by comparing the results from a simulated network model with the results measured in a distribution system, minimizing the difference between the observed and the predictive values. Obtained results of calculations with the use of both software packages have been compared with each other.

\section{DESCRIPTION OF THE RESEARCH OBJECT}

The studies were conducted in a selected part of a real water supply network, supplying water to approximately 86,000 residents. The length of the water supply network in this area equals $233.57 \mathrm{~km}$, whereas the length of water supply service line is $122.96 \mathrm{~km}$. The water supply pipes operate in a mixed - looped and branched system. The network consists of pipes made of steel, grey cast iron, ductile cast iron, PVC, PE-HD and asbestos cement. Two water supply stations, i.e. "DZ" and "ZDZ" are found in the considered area. The annual water consumption for the "DZ" and "ZDZ" stations amounts to 3,493,050 $\mathrm{m}^{3}$ and 2,223,945 $\mathrm{m}^{3}$, respectively. Fig. 1 presents the scheme of the considered water supply area with marked location of water supply stations and free chlorine measurement points. The water supply system also comprises water storage tanks. There are two water tanks with the volume of $3,860 \mathrm{~m}^{3}$ on the premises of "DZ" station, whereas four tanks with the total volume of 20,000 $\mathrm{m}^{3}$ are found in the "ZDZ" station. Water from the tanks is transmitted by means of the 


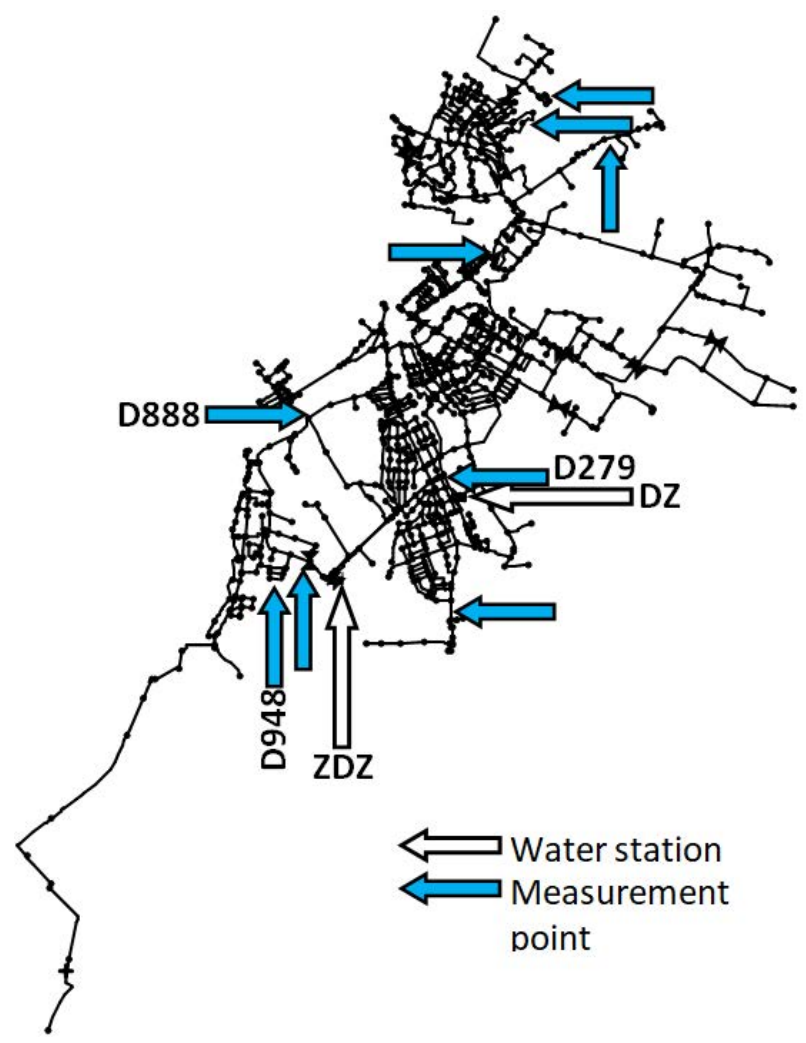

Figure 1: Location of $\mathrm{DZ}$ and $\mathrm{ZDZ}$ water intakes as well as free chloride concentration measurement points.

suction lines to the second-stage pumping station. The "DZ" second-stage pumping station is equipped with 4 pumping units; the average daily capacity in 2017 reached $9570 \mathrm{~m}^{3} / \mathrm{d}$ under the pressure of $\mathrm{p}=0.52-0.55 \mathrm{MPa}$. On the other hand, the "ZDZ" pumping station comprises three pumping units operating under the pressure of $p=0.21-0.24 \mathrm{MPa}$ and the average daily capacity of about $6093 \mathrm{~m}^{3} / \mathrm{d}$. The water in the considered area is subjected to constant disinfection performed by means of gaseous chlorine. The disinfection system is designed with the average hourly capacity $\mathrm{Q}=600 \mathrm{~m}^{3} / \mathrm{h}$. The chlorine concentration is set as $0.15-0.25 \mathrm{~g} / \mathrm{m}^{3}$. Additionally, water is disinfected by means of UV radiation. The dose of chlorine in "ZDZ" station is adjusted to the current flux from the intake.

\section{RESEARCH METHODOLOGY}

The collection of data necessary for the construction and calibration of the water quality model was connected with conducting laboratory and field studies as well as model research.

\subsection{Laboratory research}

The aim of laboratory research was to determine the value of the coefficient of chlorine concentration change $\mathrm{k}_{\mathrm{b}}$ in the mass of water, which was determined using the water collected from the "DZ" station, supplying the considered network. Its value was determined for two 
time spans: from 0 to 7 hours and over 7 hours. Such a division resulted from the fact that chlorinated water, prior to introduction to the network, resided in a tank for about 7 hours. On the basis of the relation describing the changes in chlorine concentration in the function of time $(\mathrm{t}>7 \mathrm{~h})$, the constant of chlorine decay in the mass of water $\mathrm{k}_{\mathrm{b}}$ was determined by obtaining the linear slope $(a=\operatorname{tg} \alpha)$ calculated through approximation of the results produced in a laboratory. The linear slope corresponds to the constant of chloride decay $\mathrm{k}_{\mathrm{b}}$ and equals $0.0019 \mathrm{~h}^{-1}$. While determining the linear slope, the coefficient of determination $\mathrm{R}^{2}=0.809$.

\subsection{Field research}

For the purpose of model calibration, 9 free chlorine concentration measurement points were selected in the water supply network (Fig. 1). The location of measurement points was chosen using the hydraulic network model, determining the age of water in the range from $1 \mathrm{~h}$ to 200h. The studies were conducted by means of a mobile measuring set-up (Fig. 2). The measurements were performed in chambers, which allowed for the preparation of water measurement point and installation of the measurement device. The measurements were carried out in a continuous manner, for $48 \mathrm{~h}$. The water collected from the measurement points, after the network was flushed and the pressure reduced, was transferred through an elastic hose with the diameter of $10 \mathrm{~mm}$ to a flow assembly equipped with chlorine and $\mathrm{pH}$ sensors.

The measurement of free chlorine was carried out by means of a Chloromax CCS142D sensor, with the measurement range of free active chlorine $(\mathrm{HOCl})$ from 0.01 to $5 \mathrm{mg} / \mathrm{dm}^{3}$ and the maximum measurement error of $1 \%$.

Digital data transmission from the sensors to the measurement system was performed through a contactless inductive coupler. The data were saved in the device memory in 10minute intervals. The scheme of the measuring set-up was presented in Fig. 2. The patterns for changes in chlorine concentration at "DZ" and "ZDZ" water supply stations were prepared for the water quality model.

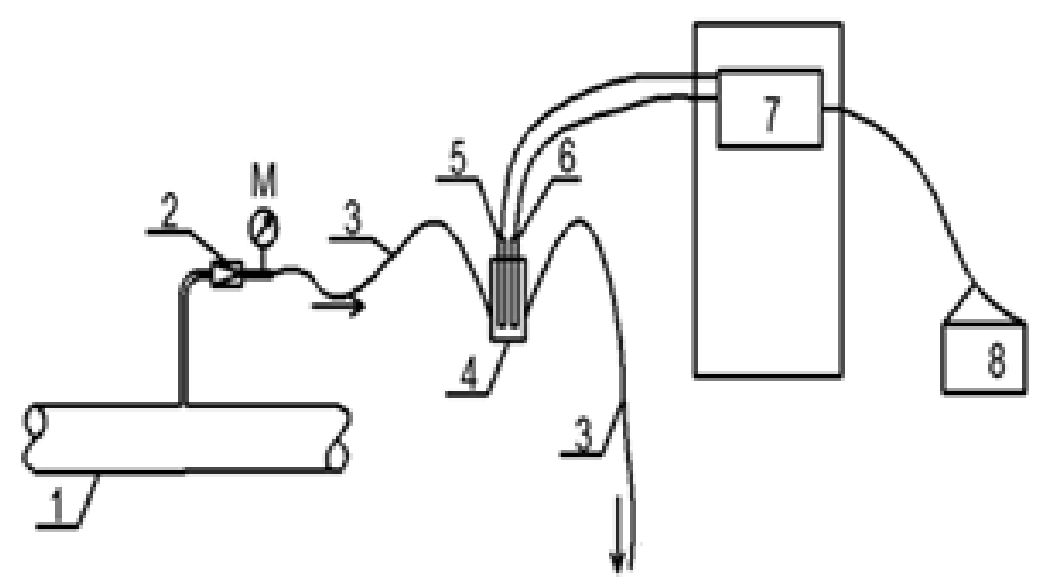

Figure 2: Scheme of a mobile measuring set-up: 1 - water supply pipe, 2 - pressure reduction valve, 3 - Elastic hose, 4 - Flowfit CCA250 flow assembly, 5 Chloromax CCS142D chlorine sensor, 6 - CPS11D pH sensor, 7 - measurement system equipped with Liquiline M CM330 transmitter, 8 - power supply (battery), $\mathrm{M}$-manometer. 


\subsection{Construction and calibration of water quality models using EPANET 2.0 and WaterGEMS software}

In the first stage of simulation calculations, a hydraulic model of the network was prepared in EPANET 2.0 software. For the purposes of the hydraulic model calibration fire-flow tests have been performed to calculate head loss on a set of pipes that was representative of range of pipe materials [25]. These tests enabled to calculate roughness factors of the pipes, used as input parameters during calibration process. To calibrate hydraulic model in EPANET 2.0 software, a trial and error method has been used. Calibration involved adjustment in various model parameters so that the model agreed with field measurements of flow and pressure. Calibration of the hydraulic model in the WaterGEMS software was performed automatically by means of Darwin Calibrator optimization module, based on the genetic algorithm. Calibration was performed using the same values of pressure and flow rate measurements as in the EPANET software. The pipe roughness and the node water demand variation was assumed in the range 0.5 to 1.5 initial values. The construction of water quality model began when the hydraulic model was successfully calibrated and basic input data was collected.

Each time, the modelling of water quality requires inputting boundary conditions for a given simulation. Dirichlet boundary condition was assumed as basic, reflecting the chlorine concentration at the water station outlet to the network (source concentrations). The abovementioned concentration value can be introduced into the system as a constant value or presented as a pattern. The study involved preparation and use of chlorine concentration patterns at "DZ" and "ZDZ" water supply stations. The chlorine concentration values within a distribution network are lower than in the source due to the dissipation of disinfecting agent and are calculated in accordance with the assumed zero-, first- or higher-order reaction equation. A first-order chlorine decay model was employed in simulation using EPANET software, both by the pipe wall $\left(\mathrm{k}_{\mathrm{w}}\right)$ and in the water mass $\left(\mathrm{k}_{\mathrm{b}}\right)$. The simulations were performed within a 120 -h time span with 10 minute time steps. The $\mathrm{k}_{\mathrm{w}}$ coefficient was determined by trial-and-error during the calibration process. The calibration file was devised on the basis of chlorine concentration measurements in 9 selected spots of water supply network (Fig. 1). The aim of the calibration was to adjust the $\mathrm{k}_{\mathrm{w}}$ coefficient value so that the concentration of chlorine in water would match the actual concentrations in selected measurement spots. The best results were obtained for the $\mathrm{k}_{\mathrm{w}}$ coefficient equal to $0.041 \mathrm{~h}^{-1}$.

Designing the water quality model in WaterGEMS software was analogous to that in EPANET 2.0. When a calibrated hydraulic water supply network model and basic input data were obtained, the construction of water quality model in that software could begin. Similarly, to the previous case, a first-order chlorine decomposition model was applied both at the pipe wall $\left(\mathrm{k}_{\mathrm{w}}\right)$ and water mass $\left(\mathrm{k}_{\mathrm{b}}\right)$. The simulations were performed in Water Quality Batch Run module for the time span of $120 \mathrm{~h}$ with 10-minute time steps, in a trial-and-error manner through the comparison of chlorine concentration value calculated by the software and measured in the given flow assembly. The best goodness of fit for graphs was obtained in the case of the $\mathrm{k}_{\mathrm{w}}$ value equal to $0.05 \mathrm{~h}^{-1}$.

\section{RESULTS AND DISCUSSION}

As can be seen in the figures, the changes of chlorine concentration obtained in both software packages are similar. A slightly better adjustment of the calculations to the measured values was obtained in the WaterGEMS software. The comparison of errors, correlation coefficient and coefficient of determination for both packages is presented in Table 1. 
Table 1: Comparison of statistics for EPANET 2.0 and WaterGEMS.

\begin{tabular}{|c|c|c|c|c|}
\hline Mean error & RMS error & $\begin{array}{c}\text { Correlation } \\
\text { coefficient R }\end{array}$ & $\begin{array}{c}\text { Coefficient of } \\
\text { determination } \mathbf{R}^{\mathbf{2}}\end{array}$ \\
\hline EPANET & $\begin{array}{c}0.028 \\
26 \% \text { of mean } \\
\text { observed value }\end{array}$ & $\begin{array}{c}27 \% \text { of mean } \\
\text { observed value }\end{array}$ & 0.937 & 0.878 \\
\hline WaterGEMS & $\begin{array}{c}0.020 \\
21 \% \text { of mean } \\
\text { observed value }\end{array}$ & $\begin{array}{c}0.031 \\
22 \% \text { of mean } \\
\text { observed value }\end{array}$ & 0.946 & 0.895 \\
\hline
\end{tabular}

The best adjustment of the simulated values with field measurements was obtained for the points closest to the water supply stations - e.g. D279, (Figs 3 and 4) in both software packages. As the disinfectant moves through the network the concentration of chlorine decreases. The larger measurement differences occurred at the farther points from the water station outlet - e.g. D948 (Figs 5 and 6), and at the point where mixing of water streams from two water stations takes place - D888.

Fig. 7 shows a comparison of the free chlorine concentration changes for the exemplary node D948 calculated in the EPANET 2.0 and WaterGEMS software and the field measurement data. It can be observed in the figure that the estimated trend of the chlorine concentration obtained in WaterGEMS is similar to the trend of the field measurement values. But differences in the obtained mean values are not significant. It confirms that carefully calibrated hydraulic model can give good results in EPANET 2.0 free software as well as in commercial WaterGEMS package.

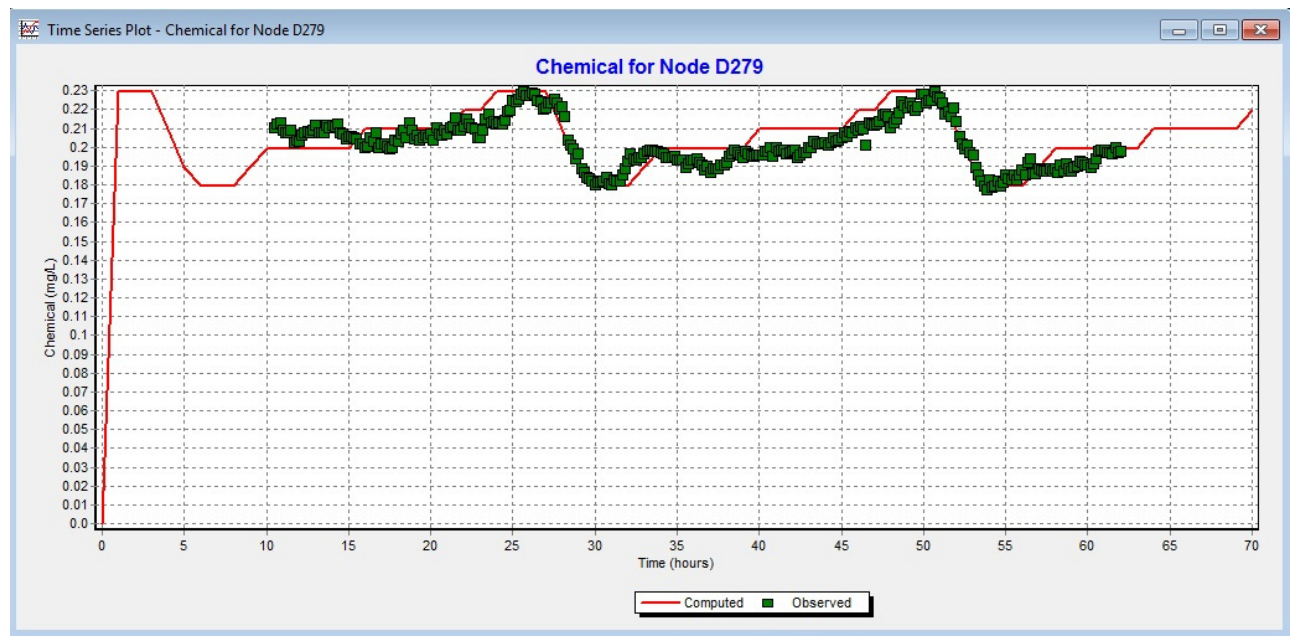

Figure 3: Changes of free chlorine concentration obtained in EPANET 2.0 software at node D279 (computed - solid line, observed - points). 


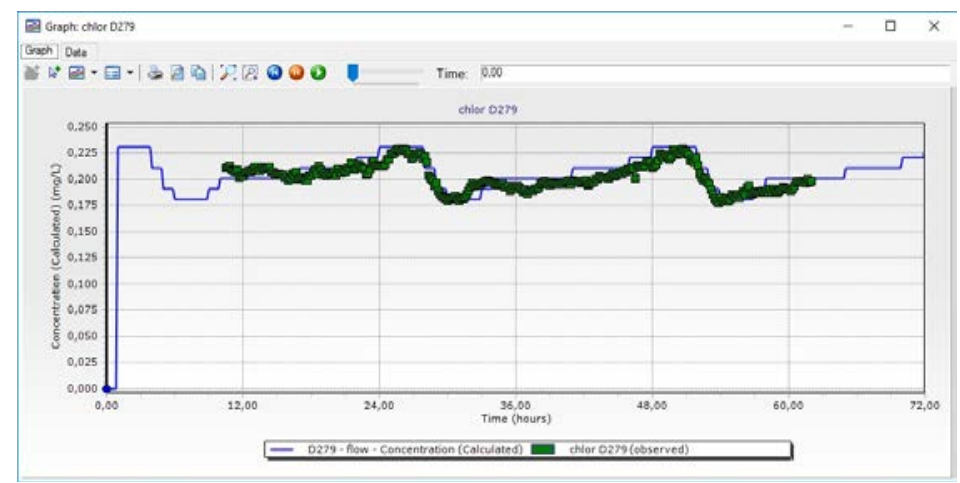

Figure 4: Changes of free chlorine concentration obtained in WaterGEMS software at node D279 (computed - solid line, observed - points).

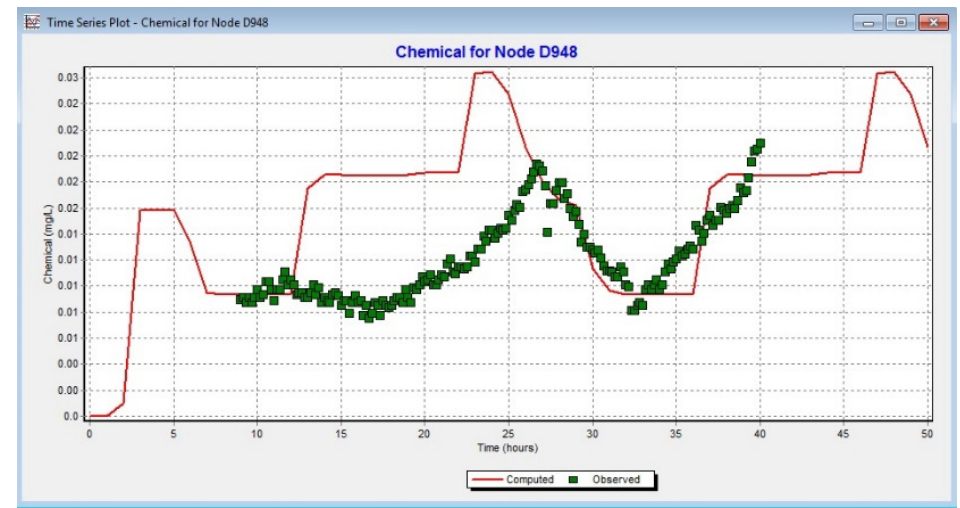

Figure 5: Changes of free chlorine concentration obtained in EPANET 2.0 software at node D948 (computed - solid line, observed - points).

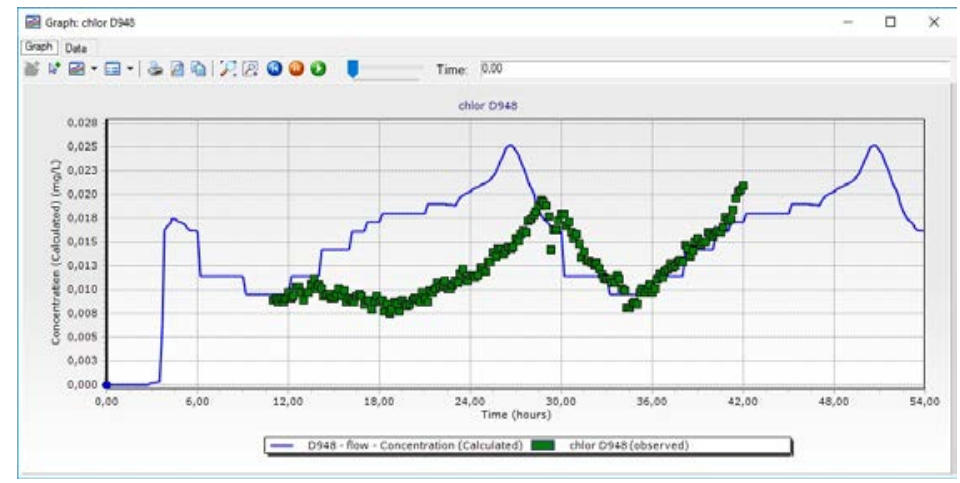

Figure 6: Changes of free chlorine concentration obtained in WaterGEMS software at node D948 (computed - solid line, observed - points). 


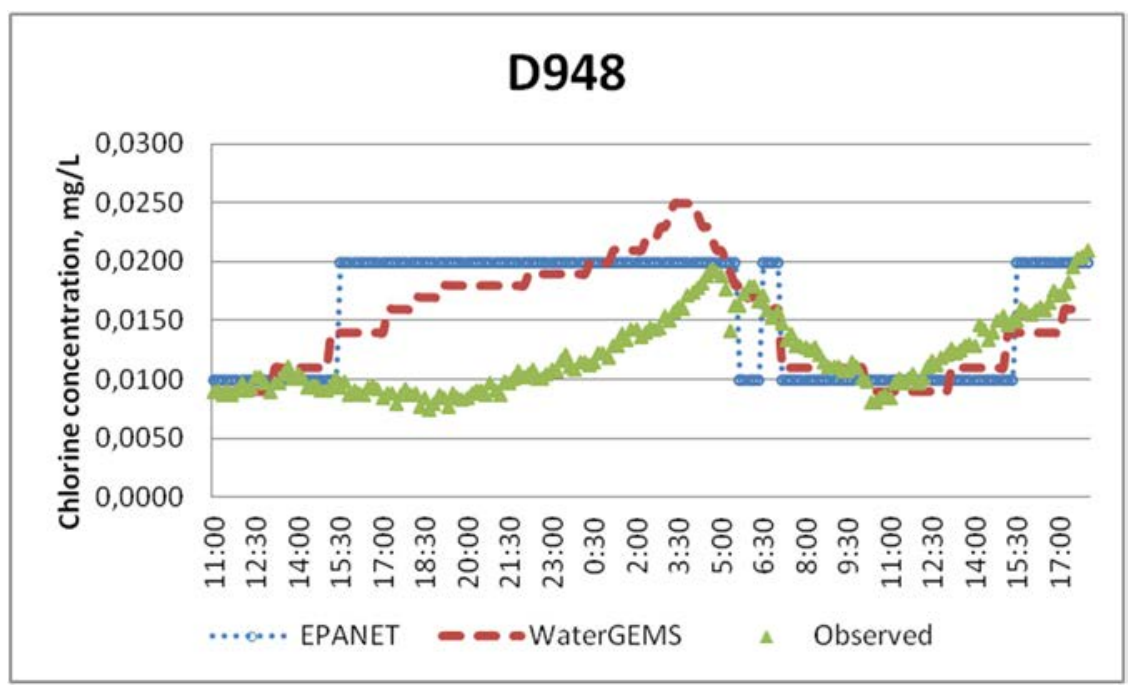

Figure 7: Comparison of changes in observed and calculated free chlorine concentrations.

\section{CONCLUSIONS}

- Construction of a numerical water quality model is a complex and difficult process. Significant difficulties arise both at the stage of the implementation of the measurement campaign and the calibration process of the model. In the case of the presented network, a special, mobile measuring set-up was constructed to perform continues chlorine concentration measurements.

- The use of WaterGEMS software enabled the automatic calibration of the hydraulic model with the use of a genetic algorithm, but the calibration of the water quality model was carried out by trial and error method. In EPANET 2.0 both hydraulic and water quality model were calibrated using trial and error method, which extended the calculation time.

- The changes of chlorine concentration mean values obtained in both software packages are similar. A slightly better adjustment of the calculations to the measured values was obtained in the WaterGEMS software.

- The best adjustment of the simulated values with field measurements was obtained for the points closest to the water supply stations in both software packages. The larger measurement differences occurred at the farther points from the water station outlet.

\section{ACKNOWLEDGEMENT}

This paper was financed by statutory activity of the Faculty of Environmental Engineering, Lublin University of Technology.

\section{REFERENCES}

[1] Kim, H.J., Kim, S. \& Koo, J., Modelling chlorine decay in a pilot scale water distribution system subjected to transient. Procedia Engineering, 119, pp. 370-378, 2015.

[2] Rossman, L.A., Clark, R.M. \& Grayman, W.M., Modeling chlorine residuals in drinking-water distribution systems. J. Environ. Eng., 120(4), pp. 803-820, 1994. 
[3] Clark, R.M., Rossman, L.A. \& Wymer, L.J., Modeling distribution system water quality: Regulatory implications. J. Water Resour. Plan. Mang., ASCE, 121(6), pp. 423-428, 1995.

[4] Boccelli, D.L., Tryby, M.E., Uber, J.G. \& Summers, R.S., A reactive species model for chlorine decay and THM formation under rechlorination conditions. Water Res., 37, pp. 2654-2666, 2003.

[5] Ahn, J.Ch., Lee, S.W., Choi, K.Y. \& Koo, J.Y., Application of EPANET for the determination of chlorine dose and prediction of THMs in a water distribution system. Sustain. Environ. Res., 22(1), pp. 31-38, 2012.

[6] Vieira, P., Coelho, S.T. \& Loureiro, D., Accounting for the influence of initial chlorine concentration, TOC, iron and temperature when modelling chlorine decay in water supply. J. Water Supply: Res. Technol.-AQUA, 53(7), pp. 453-467, 2004.

[7] Warton, B., Heitz, A., Joll, C. \& Kagi, R., A new method for calculation of the chlorine demand in natural and treated waters. Water Res., 40, pp. 2877-2884, 2006.

[8] Courtis, B.J., West, J.R. \& Bridgeman, J., Temporal and spatial variations in bulk chlorine decay within a water supply system, J. ASCE. Environ. Eng., 135(3), pp. 147$152,2009$.

[9] LeChevalier, M.W., Coliform regrowth in drinking water: A review. J. Am. Water Works Assoc., 82(11), pp.74-86, 1990.

[10] Al-Jasser, A.O., Chlorine decay in drinking-water transmission and distribution systems: Pipe service age effect. Water Research, 41, pp. 387-396, 2007.

[11] Ramos, H., Loureiro, D., Lopes, A., Fernandes, C., Covas, D., Reis, L.F. \& Cunha, M.C., Evaluation of chlorine decay in drinking water systems for different flow conditions: From theory to practice. Water Resources Management, 24(4), pp. 815834. 2010.

[12] Kim, H., Kim, S. \& Koo, J., Prediction of chlorine concentration in various hydraulic conditions for a pilot scale water distribution system. Procedia Engineering,70, pp. 934-942, 2014.

[13] Nejjari, F. et al., Chlorine decay model calibration and comparison: application to a real water network. Procedia Engineering, 70, pp. 1221-1230, 2014.

[14] Vasconcelos, J.J., Boulos, F.P. \& Grayman, W.M., Characterization and Modeling of Chlorine Decay in Distribution Systems, AWWA Publishing: Denver, CO, pp. 110116, 180-185, 272-273, 1996.

[15] Powell, J.C., Hallam, N.B., West, J.R., Forster, C.F. \& Simms, J., Factors which control bulk chlorine decay rates. Water Research, 34(1), pp. 117-126, 2000.

[16] Musz, A., Kowalska, B. \& Widomski, M., Some issues concerning the problems of water quality modeling in distribution system. Ecol, Chem, Eng, S., 16(S2), 2009.

[17] Roopali, V., Goyal, H. \& Patel, M., Analysis of residual chlorine in simple drinking water distribution system with intermittent water supply. Appl. Water Sci., 5, pp. 311$319,2015$.

[18] Liou, C.P. \& Kroon, J.R., Modeling the 2015 propagation of waterborne substances in distribution networks. J. Am. Water Works Assoc., 79(11), pp. 54-58, 1987.

[19] Rossman, L.A., Clark, R.M. \& Grayman, W.M., Modeling chlorine residuals in drinking-water distribution systems. J. Environ. Eng., 120(4), pp. 803-820, 1994.

[20] Rossman, L.A. \& Boulos, P.F., Numerical method for modeling water quality in distribution system: A comparison. J. Water Resour. Plann. Manage., 122(2), 1996.

[21] Islam, M.R., Chaudhry, M.H., \& Clark, R.M., Inverse modeling of chlorine concentration in pipe networks under dynamic conditions. J. Environ. Eng., ASCE, 123(10), pp. 1033-1044, 1997. 
48 Urban Water Systems \& Floods II

[22] Ucak, A. \& Ozdemir, O.N., Simulation of chlorine decay in drinking water distribution systems. ASCE Conference Proceedings, Water Distribution Systems Analysis, pp. 1$11,2004$.

[23] Leeuwen, J.V., Daly, R. \& Holmes, M., Modeling the treatment of drinking water to maximize dissolved organic matter removal and disinfection by-product formation. Desalination, 176(1-3), pp. 81-89, 2004.

[24] Hua, F., West, J.R., Barker, R.A. \& Forster, C.F., Modelling of chlorine decay in municipal water supplies. Water Research, 33(12), pp. 2735-2746, 1999.

[25] Modeling and Management: A Reference Guide for Utilities. USEPA: Cincinnati, OH, 2005. 